\title{
Electrospun polyimide ultrafine non-woven fabrics with high whiteness and good thermal stability from organo-soluble semi-alicyclic polyimides: Preparation and properties
}

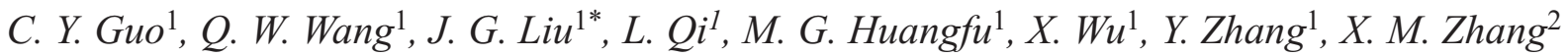 \\ ${ }^{1}$ Beijing Key Laboratory of Materials Utilization of Nonmetallic Minerals and Solid Wastes, National Laboratory of \\ Mineral Materials, School of Materials Science and Technology, China University of Geosciences, 100083 Beijing, China \\ ${ }^{2}$ School of Electrical Engineering, Beijing Jiaotong University, 100044 Beijing, China
}

Received 29 January 2019; accepted in revised form 20 March 2019

\begin{abstract}
A series of organo-soluble polyimide (PI) resins were synthesized by a two-step chemical imidization reaction from two semi-alicyclic dianhydrides, 1,4-dihydroxyphenyl-dicyclohexanecarboxylate-3,3',4,4'-tetracarboxylic acid dianhydride (HTA-HQ, I) and 4,4'-dihydroxybiphenyl dicyclohexanecarboxylate-3,3',4,4'-tetracarboxylic acid dianhydride (HTA$\mathrm{BP}, \mathrm{II}$ ) and two rigid-rod aromatic diamines, 2,2'-dimethylbenzidine (DMBZ, a) and 2,2'-bis(trifluoromethyl)benzidine (TFMB, b), respectively. Then, PI ultrafine non-woven fabrics were successfully fabricated via a one-step electrospinning procedure with the synthesized semi-alicyclic PI resins dissolved in $N, N$-dimethylacetamide (DMAc), followed by heat treatment at $200^{\circ} \mathrm{C}$. Comparatively, the standard wholly aromatic PI fabric, poly(pyromellitic dianhydride-oxydianiline) (PI-ref, PMDA/ODA) was prepared by a two-step electrospinning procedure with poly(amic acid) (PAA), followed by the high-temperature imidization procedure up to $350^{\circ} \mathrm{C}$. The derived electrospun semi-alicyclic PI non-woven fabrics exhibited much higher optical reflectance and whiteness than that of the PI-ref. For example, PI-II $\mathrm{b}$ (HTA-BP/TFMB) fabric showed an optical reflectance $\left(R_{457}\right)$ value of $90.6 \%$ at the wavelength of $457 \mathrm{~nm}$ and whiteness index $(W I)$ of 92.7 , which were quite higher than those of PI-ref $\left(R_{457}: 37.3 \%\right.$; WI: 59.0). In addition, the semi-alicyclic PI fabrics exhibited good thermal stability with the glass transition temperatures $\left(T_{\mathrm{g}}\right)$ higher than $217^{\circ} \mathrm{C}$.
\end{abstract}

Keywords: thermal properties, polyimide, electrospinning, whiteness, solubility

\section{Introduction}

Polyimide (PI) represents a class of high performance heteroaromatic polymers characterized by excellent comprehensive properties, including high thermal and thermo-oxidative stability, excellent mechanical and dielectric properties, and good environmental resistance [1-5]. All of the performance advantage of the wholly aromatic PIs benefit from the strong intra- and intermolecular interactions originated from the highly conjugated molecular skeletons in the polymer chains [6]. This structural feature for the wholly aromatic PIs, however, sometimes might sacrifice the desirable properties for specific applications. For instance, as far as the optical properties are concerned, the intrinsic charge transfer complex (CTC) originated from the interaction of the electron-donating diamine moiety and the electron-accepting dianhydride moiety in the wholly aromatic PIs might cause an extraordinary absorption of visible light, inducing the deep colors and relatively low optical transparency for the polymer films [7-11]. On the other hand, the strong interaction between the 
molecular chains will inevitably deteriorate the solubility and processability of the wholly aromatic PIs [12-14]. Thus, although the wholly aromatic PIs have been widely used in aviation, aerospace, electrical and electronic engineering for more than half a century since their first commercialization in 1960s, their applications in optoelectronic and other related areas requiring materials with high transparency, low color or high whiteness have been severely obstructed by the property deficiency of the conventional wholly aromatic PIs [15].

Recently, polymer ultrafine non-woven fabrics with high whiteness and high optical reflectance have been highly desired in advanced optoelectronic fabrication, such as the recently reported electrospun high-whiteness poly(lactic-co-glycolic acid) (PLGA) ultrafine fabrics designed for improving the luminous efficiency of white light emitting diode (LED) devices [16]. Although the developed PLGA ultrafine fabrics exhibited high reflecting and scattering ability for the LED light sources, their thermal stability was relatively poor. Thus, the long-term thermal reliability and anti-yellowing issues have to be addressed for their practical applications for LED and other solid state lighting devices. Besides the potential applications as reflectors for LED devices, the polymeric ultrafine fabrics with good thermal stability might find various applications in modern industry, such as light shielding layer for textiles [17], thermal retaining clothing [18], and base materials for new colored woven fabric design [19], and so on.

Generally, the optical applications of the electrospun polymeric membranes are affected by both of the polymers themselves and the electrospinning conditions. On one hand, the pristine polymer should possess good optical properties, low curing temperature, and good thermally oxidative stability. On the other hand, the microscopic morphology of the polymer fibers adjustable by the electrospinning fabrication should also meet the demands of specific optical applications. For example, one can achieve high whiteness of specific polymer ultrafine fabrics by adjustment of the diameters of the fibers, or introduction of highly disordered nanostructures induced from the bead-like shape, rod-like scatterers, micropores, and so on [20]. From such point of view, electrospun PI ultrafine fabrics with high whiteness might be good candidates for such applications due to their intrinsic thermal stability. Actually, electrospun wholly aromatic PI fabrics and their composites have been widely investigated as high performance components in high-tech applications, such as separators for Li-ion, Li-S, Li-O $\mathrm{O}_{2}$ battery [21], low-dielectricconstant insulators for microelectronic devices [22], membranes for wastewater treatment [23], superhydrophobic surfaces for self-cleaning and antifouling applications [24], and so on. In the practical applications, the electrospun PI fabrics exhibited good comprehensive properties [25-31]. The progress on the research and develop of the electrospun wholly aromatic PI ultrafine fibers has been reviewed recently $[32,33]$. However, most of the reported ultrafine PI non-woven fabrics exhibited deep colors from pale-brown to deep yellow.

Up to now, to the best of our knowledge, few works have been reported on the research and development of PI ultrafine non-woven fabrics with high whiteness and high optical reflectance. In order to achieve the purpose, various efforts have been performed with the aim of improving the optical properties of the standard PIs while maintaining their intrinsic property merits in the past decades. At present, all of the modification methods are basically based on how to reduce the formation of CTCs inside the PI molecular chains. Several methodologies, including introduction of non-aromatic units, highly electronegative substituents, bulky groups, or meta-substituted structures into the PI molecular chains have been widely used to develop colorless and transparent PIs [34-36].

Inspired by these ideas, we tried to introduce the above-mentioned groups or chemical structures into the PI molecular chains and prepared a series of fluorine-containing PI ultrafine non-woven fabrics with both of high heat resistance and high whiteness very recently [37]. The PI fabrics were fabricated using the soluble fluoro-containing PIs as the starting materials instead of conventional poly(amic acid) (PAA) precursors. Electrospun PI fibers via PAA usually exhibited exceptionally high mechanical properties [38-40]. However, the mechanical properties of the PAA-derived ultrafine fibers are often deteriorated by the fusion of the nanofilaments or pinholes in the obtained PI nanofibers during the high-temperature dehydration and imidization reaction at elevated temperatures $\left(>300^{\circ} \mathrm{C}\right)$ [41]. Electrospinning fabrication via soluble PIs can usually eliminate the drawbacks of the PAA procedure and afford the derived PI fibers good mechanical properties.

In our previous work, the derived wholly aromatic fluoro-containing PI fabrics showed somewhat high 
yellow indices $\left(2.98 \leq b^{*} \leq 15.92\right)$ and whiteness as low as 82.1 [37]. These optical parameters need to be further improved in order to meet the property requirements of advanced optoelectronic applications. Thus, in the current work, as one of our continuous efforts developing high performance heat-resistant optical polymer components for advanced optoelectronic applications, a series of PI ultrafine nonwoven fabrics with high whiteness were developed with another idea instead of introducing aromatic fluoro-containing substituents. For this purpose, two semi-alicyclic dianhydrides were synthesized and characterized. Then, the dianhydrides were polymerized with two aromatic rigid-rod diamines with a twostep chemical imidization procedure to afford soluble PI resins. The effects of the molecular structures of the derived semi-alicyclic PIs on their molecular weight and solubility were studied. Then, a series of PI ultrafine non-woven fabrics were prepared with the soluble PI solution as the starting materials. The structure-property relationship of the PI fabrics was investigated in detail.

\section{Experimental}

\subsection{Materials}

2,2'-Dimethylbenzidine (DMBZ) and 2,2'-bis(trifluoromethyl)benzidine (TFMB) were purchased from Changzhou Sunlight Pharmaceutical Co., Ltd. (Jiangsu, China), and dried in vacuo at $80^{\circ} \mathrm{C}$ for $12 \mathrm{~h}$ prior to use. Hydrogenated trimellitic anhydride chloride (HTAC) was synthesized in our laboratory according to the literature [42]. Hydroquinone and 4,4'bisphenol were purchased from Sigma-Aldrich China (Shanghai, China) and used as received. $N$-methyl2-pyrrolidinone (NMP), $N, N$-dimethylacetamide (DMAc), $N, N$-dimethylforamide (DMF) were purchased from Tokyo Chemical Industry (Tokyo, Japan), and distilled prior to use and stored under $4 \AA$ molecular sieve. The other commercially available reagents including $\mathrm{m}$-cresol, tetrahydrofuran, butyl cellulose (BC) and chloroform were purchased from Tianjin Fuchen Fine Chemicals Co. Ltd. (Tianjin, China) and used as received.

\subsection{Characterization}

Inherent viscosity was measured using an Ubbelohde viscometer with a $0.5 \mathrm{~g} / \mathrm{dl} \mathrm{NMP}$ solution at $25^{\circ} \mathrm{C}$. Absolute viscosity of the PI varnish was measured using a Brookfield DV2TRVCP viscometer (Brookfield Ametek, Massachusetts, USA) at $25^{\circ} \mathrm{C}$ and a cone spindle of CPA-41Z was used. The limitation of viscosity range was 6-122 $800 \mathrm{mPa} \cdot \mathrm{s}$ for the machine. The number average molecular weight $\left(M_{\mathrm{n}}\right)$ and weight average molecular weight $\left(M_{\mathrm{w}}\right)$ of the PI resins were measured using a gel permeation chromatography (GPC) system (Shimadzu, Kyoto, Japan) with a LC-20AD dual-plunger parallel-flow pumps (D1-LC), a SIL-20A is a total-volume injection-type autosampler, a CTO-20A column oven, and a RID20A detector. HPLC grade NMP was used as the mobile phase at a flow rate of $1.0 \mathrm{ml} / \mathrm{min}$. Attenuated total reflectance Fourier transform infrared (ATRFTIR) spectrum was obtained on a Bruker Tensor27 FT-IR spectrometer (Ettlingen, Germany). Nuclear magnetic resonances $\left({ }^{1} \mathrm{H}-\mathrm{NMR}\right.$ and ${ }^{13} \mathrm{C}$-NMR) were performed on an AV 400 spectrometer (Ettlingen, Germany) operating at $400 \mathrm{MHz}$ in DMSO- $d_{6}$. Field emission scanning electron microscopy (FESEM) was carried out using a Technex Lab TinySEM 1540 (Tokyo, Japan) with an accelerating voltage of $15 \mathrm{kV}$ for imaging. Pt/Pd was spattered on each film in advance of the measurements.

Ultraviolet-visible (UV-Vis) spectra were recorded on a Hitachi U-3210 spectrophotometer (Tokyo, Japan) at room temperature. Prior to test, PI fabric samples were dried at $100^{\circ} \mathrm{C}$ for $10 \mathrm{~h}$ to remove the absorbed moisture. Whiteness of the PI nonwoven fabric was measured using an X-rite color i7 spectrophotometer (Michigan, USA) in accordance with the procedure described in Chinese standard GB/T 17644-2008 (Test method for whiteness and chromaticity of textile fibers) and in the standard of ISO 11475:2017 (Paper and board- determination of CIE whiteness, $\mathrm{D} 65 / 10^{\circ}$, outdoor daylight). The color parameters were calculated according to a CIE Lab equation. $L^{*}$ is the lightness, where 100 means white and 0 implies black. A positive $a^{*}$ means a red color, and a negative one indicates a green color. A positive $b^{*}$ means a yellow color, and a negative one indicates a blue color. The color parameters of a standard poly(pyromellitic dianhydride-oxydianiline) (PMDAODA) fabric was also measured for reference. The whiteness values of the PI mats were calculated as Equation (1):

$W=100-\left[\left(100-L^{*}\right)^{2}+a^{* 2}+b^{* 2}\right]^{1 / 2}$

where $W$ standards for whiteness, $L^{*}$ standards for index of lightness, $a^{*}$ and $b^{*}$ stand for chromaticity coefficient. 
Differential scanning calorimetry (DSC) was carried on a TA-Q 100 thermal analysis system (Delaware, USA) at a heating rate of $10^{\circ} \mathrm{C} / \mathrm{min}$ in nitrogen. Thermogravimetric analysis (TGA) was performed on a TA-Q50 thermal analysis system (Delaware, USA) at a heating rate of $20^{\circ} \mathrm{C} / \mathrm{min}$ in nitrogen.

Solubility was investigated by mixing $1.0 \mathrm{~g}$ of the PI resin and $9.0 \mathrm{~g}$ of the solvent tested $(10 \mathrm{wt} \%$ solid content), and then stirred for $24 \mathrm{~h}$ at room temperature. The solubility was determined visually as three grades: completely soluble $(++)$, partially soluble $(+)$, and insoluble $(-)$, wherein complete soluble indicates a homogenous and clean state without phase separation, precipitation or gel formation, and insoluble indicates no change of the resin in the appearance.

\subsection{Monomer synthesis}

The semi-alicyclic dianhydrides, including 1,4-dihydroxyphenyl dicyclohexanecarboxylate-3,3',4,4'-tetracarboxylic acid dianhydride (HTA-HQ) and 4,4'-dihydroxybiphenyl dicyclohexanecarboxylate-3,3',4,4'tetracarboxylic acid dianhydride (HTA-BP) were synthesized according to a procedure reported in our previous work [43]. They were purified by recrystallization from acetic anhydride and dried in vacuo at $100^{\circ} \mathrm{C}$ for $24 \mathrm{~h}$.

HTA-HQ. Yield: $76.7 \%$.Melting point: $261.2^{\circ} \mathrm{C}$ (DSC peak temperature). FT-IR $\left(\mathrm{KBr}, \mathrm{cm}^{-1}\right): 2949,1865$, 1786, 1750, 1495, 1388, 1331, 1298, 1188, 1146, 1036, 980, and 906. ${ }^{1} \mathrm{H}-\mathrm{NMR}$ (DMSO- $d_{6}, \mathrm{ppm}$ ): $7.18(\mathrm{~s}, 4 \mathrm{H}), 3.60-3.53(\mathrm{~m}, 2 \mathrm{H}), 3.41-3.38(\mathrm{~m}, 2 \mathrm{H})$, 2.82-2.70 (m, 2H), 2.42-2.28 (m, 2H), 2.15-1.89 (m, $4 \mathrm{H}), 1.88-1.63(\mathrm{~m}, 4 \mathrm{H})$, and $1.59-1.40(\mathrm{~m}, 2 \mathrm{H})$. Elemental analysis: calculated for $\mathrm{C}_{24} \mathrm{H}_{22} \mathrm{O}_{10}$ : $\mathrm{C}, 61.28 \%$, H, 4.71\%; Found: C, $61.13 \%$, H, 4.77\%.

HTA-BP. Yield: $78.3 \%$. Melting point: $254.4^{\circ} \mathrm{C}$ (DSC peak temperature). FT-IR ( $\left.\mathrm{KBr}, \mathrm{cm}^{-1}\right): 2947,1864$, 1788, 1750, 1493, 1462, 1384, 1330, 1297, 1199, $1145,1035,1006,951$, and $902 .{ }^{1} \mathrm{H}-\mathrm{NMR}$ (DMSO$\left.d_{6}, \mathrm{ppm}\right): 7.73-7.68(\mathrm{~m}, 4 \mathrm{H}), 7.24-7.19(\mathrm{~m}, 4 \mathrm{H})$, $3.60-3.53(\mathrm{~m}, 2 \mathrm{H}), 3.42-3.36(\mathrm{~m}, 2 \mathrm{H}), 2.84-2.75(\mathrm{~m}$, 2H), 2.41-2.33 (m, 2H), 2.10-1.96 (m, 4H), 1.88$1.69(\mathrm{~m}, 4 \mathrm{H})$, and $1.57-1.45(\mathrm{~m}, 2 \mathrm{H})$. Elemental analysis: calculated for $\mathrm{C}_{30} \mathrm{H}_{26} \mathrm{O}_{10}$ : C, $65.93 \%, \mathrm{H}, 4.80 \%$; Found: C, $65.30 \%, \mathrm{H}, 4.85 \%$.

\subsection{Polymer synthesis}

Four PIs, including PI- $\mathrm{I}_{\mathrm{a}}$ (HTA-HQ/DMBZ), PI-I $\mathrm{I}_{\mathrm{b}}$ (HTA-HQ/TFMB), PI-II ${ }_{\mathrm{a}}$ (HTA-BP/DMBZ) and
PI-II ${ }_{b}$ (HTA-BP/TFMB) were synthesized via a twostep chemical imidization procedure with NMP as the solvent and acetic anhydride $\left(\mathrm{Ac}_{2} \mathrm{O}\right)$ as the dehydrating agent. The characteristic $\mathrm{PI}_{-} \mathrm{II}_{\mathrm{b}}$ was synthesized according to a procedure as follows. The aromatic diamine TFMB (32.0230 g, $0.1 \mathrm{~mol})$ was first dissolved in newly distilled NMP (300 g)in a $1000 \mathrm{ml}$ three-necked, round-bottomed flask equipped with a mechanical stirrer, an ice-water bath and a nitrogen inlet. The diamine solution was stirred under an ice-water bath $\left(<10^{\circ} \mathrm{C}\right)$ in a nitrogen atmosphere for $0.5 \mathrm{~h}$. Then, the dianhydride HTA-BP $(54.6520 \mathrm{~g}$, $0.1 \mathrm{~mol}$ ) was added into the diamine solution rapidly and diluted with NMP $(46.7 \mathrm{~g})$, producing a reaction mixture with a $20 \mathrm{wt} \%$ solid content. After stirring in nitrogen for $1.5 \mathrm{~h}$, the ice-bath was removed and the reaction mixture was stirred at room temperature for $20 \mathrm{~h}$. Then, a mixture of acetic anhydride $(51.0 \mathrm{~g}$, $0.5 \mathrm{~mol})$ and pyridine $(39.6 \mathrm{~g}, 0.5 \mathrm{~mol})$ was added into the system. The reaction mixture was maintained at room temperature for another $20 \mathrm{~h}$. Then, the obtained viscous solution was carefully poured into an excess of ethanol to yield a silky resin. The resin was collected and dried at $80^{\circ} \mathrm{C}$ in vacuo for 24 h. Yield: $78.9 \mathrm{~g} \mathrm{(95 \% ).}$

PI-II ${ }_{\mathrm{b}}$ (HTA-BP/TFMB). ${ }^{1} \mathrm{H}-\mathrm{NMR}$ (DMSO- $d_{6}$, ppm): $7.92(\mathrm{~s}, 2 \mathrm{H}), 7.73-7.69(\mathrm{~d}, 2 \mathrm{H}), 7.61-7.59(\mathrm{~d}, 2 \mathrm{H})$, 7.24-7.21 (d, 4H), 3.33-3.31 (m, 2H), 3.28-3.21 (m, $2 \mathrm{H}), 2.92-2.80(\mathrm{~m}, 2 \mathrm{H}), 2.46-2.35(\mathrm{~m}, 2 \mathrm{H}), 2.27-$ $2.12(\mathrm{~m}, 2 \mathrm{H}), 2.07-1.77(\mathrm{~m}, 6 \mathrm{H})$, and $1.67-1.53(\mathrm{~m}$, $2 \mathrm{H})$.

The other PI resins were prepared according to the similar procedures mentioned above except that different monomers were used.

PI-I ${ }_{\mathrm{a}}(\mathrm{HTA}-\mathrm{HQ} / \mathrm{DMBZ}) .{ }^{1} \mathrm{H}-\mathrm{NMR}$ (DMSO- $\left.d_{6}, \mathrm{ppm}\right)$ : ${ }^{1} \mathrm{H}-\mathrm{NMR}$ (DMSO- $\left.d_{6}, \mathrm{ppm}\right): 7.25-7.19(\mathrm{~m}, 10 \mathrm{H})$, $3.32-3.26(\mathrm{~m}, 2 \mathrm{H}), 3.25-3.14(\mathrm{~m}, 2 \mathrm{H}), 2.90-2.75$ (m, 2H), 2.46-2.33 (m, 2H), 2.22-2.10 (m, 2H), 2.03 $(\mathrm{s}, 6 \mathrm{H}), 2.00-1.92(\mathrm{~m}, 2 \mathrm{H}), 1.89-1.72(\mathrm{~m}, 4 \mathrm{H})$, and $1.63-1.46(\mathrm{~m}, 2 \mathrm{H})$.

PI- $\mathrm{I}_{\mathrm{b}}$ (HTA-HQ/TFMB). ${ }^{1} \mathrm{H}-\mathrm{NMR}$ (DMSO- $\left.d_{6}, \mathrm{ppm}\right)$ : $7.92(\mathrm{~s}, 2 \mathrm{H}), 7.73-7.71(\mathrm{~d}, 2 \mathrm{H}), 7.61-7.58(\mathrm{~d}, 2 \mathrm{H})$, $7.18(\mathrm{~s}, 4 \mathrm{H}), 3.31-3.29(\mathrm{~m}, 2 \mathrm{H}), 3.26-3.20(\mathrm{~m}, 2 \mathrm{H})$, 2.85-2.76 (m, 2H), 2.45-2.33 (m, 2H), 2.24-2.13 (m, $2 \mathrm{H}), 2.06-1.80(\mathrm{~m}, 2 \mathrm{H})$, and $1.67-1.53(\mathrm{~m}, 2 \mathrm{H})$. PI-II ${ }_{\mathrm{a}}(\mathrm{HTA}-\mathrm{BP} / \mathrm{DMBZ}) .{ }^{1} \mathrm{H}-\mathrm{NMR}$ (DMSO- $\left.d_{6}, \mathrm{ppm}\right)$ : 7.70-7.68 (d, 4H), 7.25-7.17 (m, 10H), 3.32-3.26 (m, 2H), 3.24-3.18 (m, 2H), 2.91-2.80 (m, 2H), 2.46-2.35 $(\mathrm{m}, 2 \mathrm{H}), 2.21-2.10(\mathrm{~m}, 2 \mathrm{H}), 2.03(\mathrm{~s}, 6 \mathrm{H}), 2.00-1.97$ $(\mathrm{m}, 2 \mathrm{H}), 1.90-1.72(\mathrm{~m}, 4 \mathrm{H})$, and $1.63-1.51(\mathrm{~m}, 2 \mathrm{H})$. 


\subsection{Fabrication of electrospinning fabrics}

First, the key solution property parameters of the developed PI resins related with the following electrospinning procedure, including the solubility in various solvents and viscosity-solid contents relationship of the PI solutions were investigated. Suitable good solvent for the PI resin and viscosity value of the obtained PI solution were determined.

Then, the soluble PI (SPI) resin, represented by PI-II was dissolved in ultra-dry DMAc at room temperature with a solid content of $25-40 \mathrm{wt} \%$, depending on the viscosities of the obtained solution. The absolute viscosities of the SPI solution were controlled to be in the range of $10000 \mathrm{mPa}$ s so as to afford ultrafine non-woven fabrics with good uniformity [37]. The pristine SPI solution was filtered through a $0.45 \mu \mathrm{m}$ polytetrafluoroethylene (PTFE) filter to remove any impurities that might block the spinneret. The SPI solution was loaded into a $5 \mathrm{ml}$ syringe and pumped through the fine hole of a spinneret by a syringe pump at a speed of $0.1 \mathrm{ml} / \mathrm{h}$. The inner diameter of the spinneret is $0.5 \mathrm{~mm}$. A voltage of $15 \mathrm{kV}$ was applied between the syringe and the rolling drum collector. The distance between the spinneret and the grounded collector was $15 \mathrm{~cm}$. Random aligned PI fibers were deposited on the aluminum foil as the support medium of the fibers, located on the rotating drum collector (diameter: $10 \mathrm{~cm}$; length: $30 \mathrm{~cm}$; speed: $200 \mathrm{rpm}$ ). The humidity in the electrospinning apparatus was controlled to be $50 \pm 2 \%$ relative humidity. The obtained PI-II $\mathrm{b}_{\mathrm{b}}$ non-woven fabric was dried at $200^{\circ} \mathrm{C}$ for $1 \mathrm{~h}$ to remove the residual solvent.

The other PI non-woven fabrics were prepared according to a similar procedure as mentioned above.

It is different from the electrospinning procedure with SPI solution as the starting material, the comparative poly(pyromellitic dianhydride-oxydianiline) (PMDA-ODA) non-woven fabric was made by a two-step procedure according to the literature [44] due to the insoluble nature of the final PI polymer. The soluble poly(amic acid) (PAA) precursor was first prepared and electrospun to obtain the PAA fiber, followed by a high temperature imidization procedure at temperatures in the range of $80-350^{\circ} \mathrm{C}$ to afford the final PI-ref (PMDA-ODA) non-woven fabric.

\section{Results and discussion}

\subsection{Monomer synthesis}

Two analogous semi-alicyclic dianhydrides were prepared by the direct esterification reaction of hy-

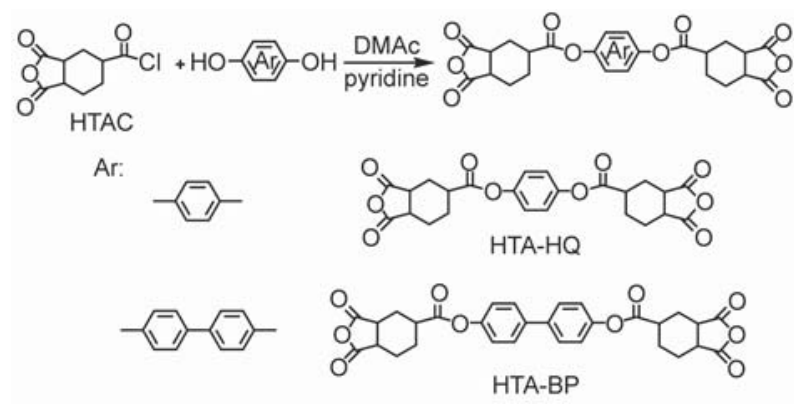

Figure 1. Synthesis of semi-alicyclic dianhydrides.

drogenated trimellitic anhydride chloride (HTAC) and hydroquinone for HTA-HQ or 4,4'-bisphenol for HTA-BP, respectively, as shown in Figure 1. The dianhydrides were designed to possess ester linkage in the molecular structure in order to afford good mechanical properties, low moisture absorption, and good thermal stability for the derived PI fabrics [45]. The dianhydrides were obtained with a good yield over $75 \%$ and easily purified by recrystallization with a solution of acetic anhydride and glacial acetic acid (3:1, volume ratio). White fine crystals with high purity were obtained for both of the dianhydrides.

The chemical structures of the ester-linked semi-alicyclic dianhydrides were confirmed by ATR-FTIR, NMR, and elemental analysis measurements. As depicted in the ATR-FTIR spectra shown in Figure 2, the HTA-HQ and HTA-BP dianhydrides exhibited characteristic absorptions at 1865 and $1786 \mathrm{~cm}^{-1}$ due to the asymmetric and symmetric stretching of the carbonyl $(\mathrm{C}=\mathrm{O})$ in the anhydride unit, respectively. In addition, the characteristic absorptions of the carbonyl $(\mathrm{C}=\mathrm{O})$ in the ester linkage $(-\mathrm{COO}-)$, the $\mathrm{C}=\mathrm{C}$ bonds in the phenyl or biphenyl units, and the $\mathrm{C}-\mathrm{O}-\mathrm{C}$ bonds in the ester moiety were all also clearly detected

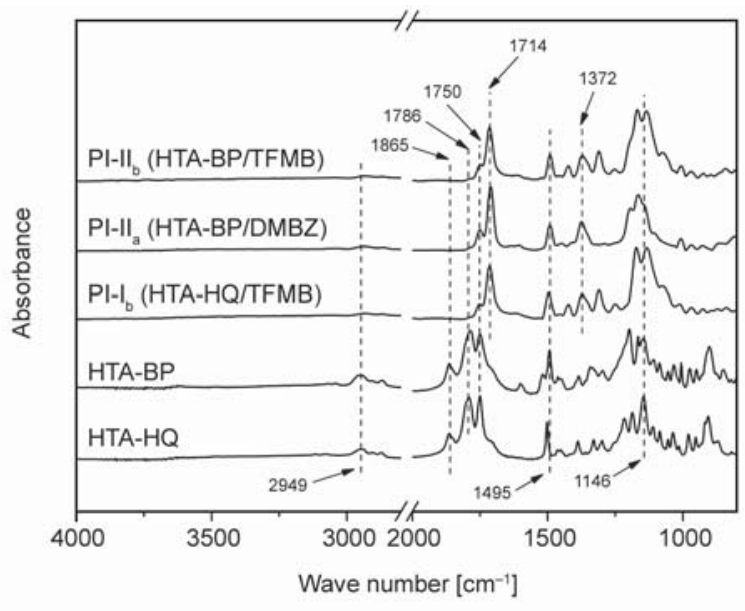

Figure 2. ATR-FTIR spectra and semi-alicyclic dianhydrides and the derived PIs. 
at 1750,1495 , and $1146 \mathrm{~cm}^{-1}$, respectively in the spectra. The absorptions around $2949 \mathrm{~cm}^{-1}$ indicated the existence of saturated $\mathrm{C}-\mathrm{H}$ bonds in the cyclohexane units. Thus, the dianhydrides were obtained with anticipated molecular structures.

The chemical structures of the semi-alicyclic dianhydrides were further confirmed by various NMR measurements and the typical results of the HTA-HQ dianhydride are shown in Figure 3. In the ${ }^{1} \mathrm{H}-\mathrm{NMR}$ spectrum (Figure 3a) of HTA-HQ, the spectrum was clearly divided into two regions. The absorption of the $\mathrm{H}$ protons (g) in the benzene unit appeared at the

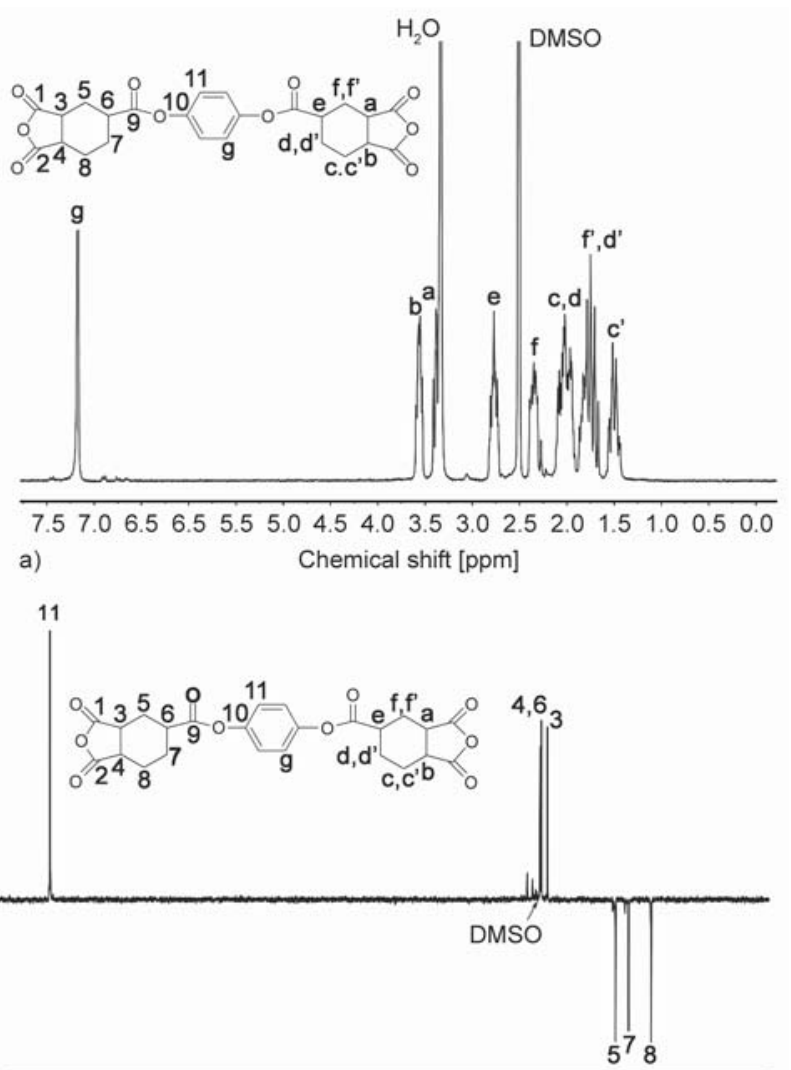

\begin{tabular}{lllllllllllll}
\hline 120 & 110 & 100 & 90 & 80 & 70 & 60 & 50 & 40 & 30 & 20 & 10 & 0 \\
b) & & & & Chemical shift [ppm] & & & & &
\end{tabular}

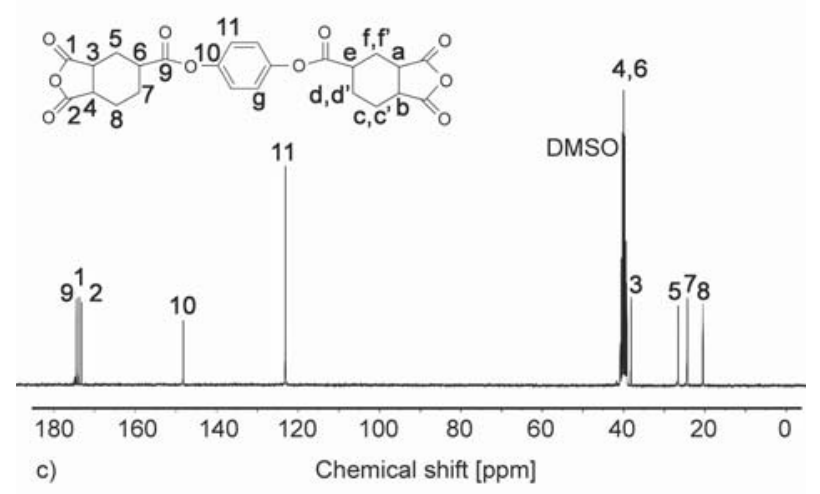

Figure 3. NMR spectra of HTA-HQ dianhydride. (a) ${ }^{1} \mathrm{H}-\mathrm{NMR}$; (b) DEPT-135; and (c) ${ }^{13} \mathrm{C}-\mathrm{NMR}$. lowest field, whereas those in the alicyclic cyclohexane moiety $(\mathbf{a}-\mathbf{f})$ at the farthest upfield in the spectrum. The three pairs of protons in the cyclohexane groups (c,c'; $\mathbf{d}, \mathbf{d}$ ' and $\left.\mathbf{f}, \mathbf{f}^{\prime}\right)$ exhibited individual absorptions in the spectrum due to the different chemical environments caused by the stereoscopic conformation of the cyclohexane unit in the dianhydride. The ${ }^{13} \mathrm{C}-\mathrm{NMR}$ spectrum of HTA-HQ was shown in Figure $3 \mathrm{c}$, together with the assignments of the observed resonances. The analysis of the complex ${ }^{13} \mathrm{C}-\mathrm{NMR}$ spectrum has benefited from the application of the distortionless enhancement by polarization transfer (DEPT-135) measurements. DEPT-135 is a useful method to determine the multiplicity of the carbon atoms. In Figure 3c, 11 signals were revealed; among which, 7 carbons induced signals in the DEPT-135 spectrum (Figure $3 b$ ) due to the attached protons. This result is consistent with the proposed structure.

In addition, the elemental analysis results also revealed the successful preparation of the target dianhydrides. The characterization results demonstrated that the polymerization grade semi-alicyclic dianhydrides were successfully synthesized and could be used for the following PI resin preparation.

\subsection{Polyimide synthesis}

Four semi-alicyclic PIs were synthesized from the two dianhydrides and two aromatic diamines via a two-step chemical imidization procedure, as shown in Figure 4. All the polymerization proceeded
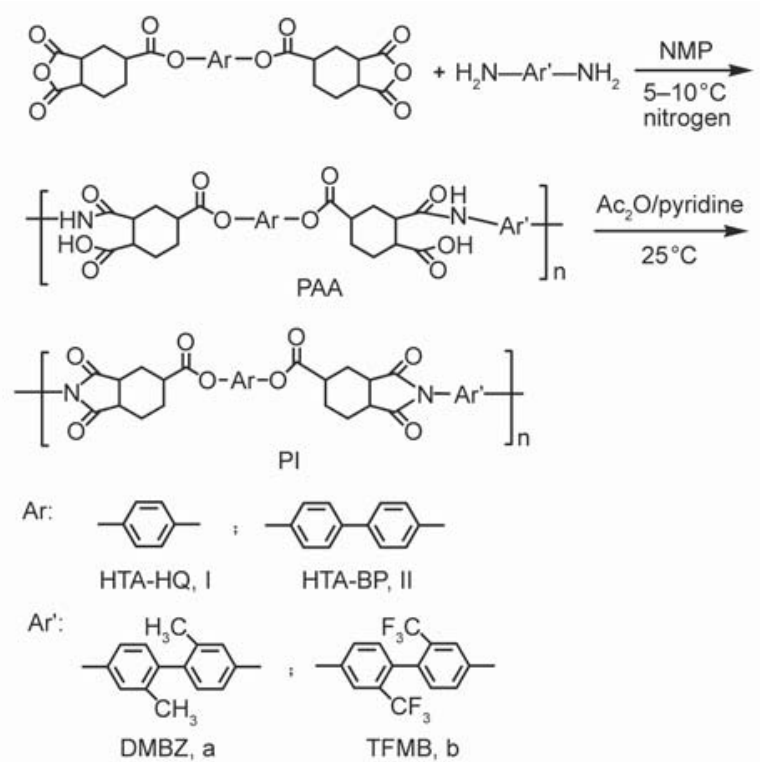

Figure 4. Synthesis of semi-alicyclic PI resins. 
Table 1. Inherent viscosities and molecular weights of PI resins.

\begin{tabular}{|c|c|c|c|c|}
\hline \multirow{2}{*}{ PI } & \multirow{2}{*}{$\begin{array}{c}{[\boldsymbol{\eta}]_{\mathbf{i n h}}{ }^{\mathrm{a}}} \\
{[\mathbf{d l} / \mathbf{g}]}\end{array}$} & \multicolumn{3}{|c|}{$\begin{array}{c}\text { Molecular weight } \\
{[\mathbf{g} / \mathbf{m o l}]}\end{array}$} \\
\cline { 3 - 5 } & & $\boldsymbol{M}_{\mathbf{n}}$ & $\boldsymbol{M}_{\mathbf{w}}$ & $\boldsymbol{M}_{\mathbf{w}} / \boldsymbol{M}_{\mathbf{n}}$ \\
\hline $\mathrm{PI}_{\mathrm{I}} \mathrm{I}_{\mathrm{a}}$ & 0.87 & 25955 & 42592 & 1.64 \\
\hline $\mathrm{PI}_{\mathrm{b}}$ & 0.62 & 22531 & 36025 & 1.60 \\
\hline $\mathrm{PI}_{\mathrm{b}} \mathrm{II}_{\mathrm{a}}$ & 0.94 & 53127 & 95362 & 1.79 \\
\hline $\mathrm{PI}_{\mathrm{n}} \mathrm{II}_{\mathrm{b}}$ & 0.69 & 36485 & 61604 & 1.69 \\
\hline
\end{tabular}

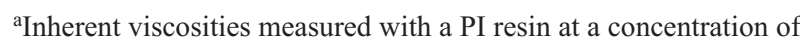
$0.5 \mathrm{~g} / \mathrm{dl}$ in NMP at $25^{\circ} \mathrm{C}$.

homogeneously in NMP and PI resins with moderate to high molecular weights were obtained. The intrinsic viscosities $\left([\eta]_{\text {inh }}\right)$ of the resulting PI resins were in the range of $0.62-0.94 \mathrm{dl} / \mathrm{g}$ measured at $25^{\circ} \mathrm{C}$ in NMP (Table 1). The obtained PI resins have a numerical average molecular weight $\left(M_{\mathrm{n}}\right)$ of $22531 \sim$ $53127 \mathrm{~g} / \mathrm{mol}$ determined by GPC measurements (Table 1). Basically, the PIs derived from DMBZ exhibited both of higher $[\eta]_{\text {inh }}$ and $M_{\mathrm{n}}$ values than those of their TFMB analogues. This is mainly due to the relatively inferior reactivity of the TFMB diamine caused by the electron-withdrawing $-\mathrm{CF}_{3}$ substituents in the diamine. Nevertheless, the molecular weights of the current PI resins were high enough for the following electrospinning fabrication.

The chemical structures of PI resins were confirmed by the ATR-FTIR spectra depicted in Figure 1. When comparing the spectra of the PIs and the dianhydride monomers, one can clearly find that the characteristic absorptions of the carbonyl $(\mathrm{C}=\mathrm{O})$ in the dianhydride $\left(1865\right.$ and $\left.1786 \mathrm{~cm}^{-1}\right)$ disappeared in the spectra of the PIs. Instead, the characteristic absorption of various imide unit, including the absorptions at $1750 \mathrm{~cm}^{-1} \quad\left(v_{\mathrm{as}, \mathrm{C}=\mathrm{O}}\right), \quad 1714 \mathrm{~cm}^{-1} \quad\left(v_{\mathrm{s}, \mathrm{C}=\mathrm{O}}\right)$, and $1372 \mathrm{~cm}^{-1}\left(v_{\mathrm{C}-\mathrm{N}}\right)$ were all detected. This proved the successful transition from the monomers to polymers

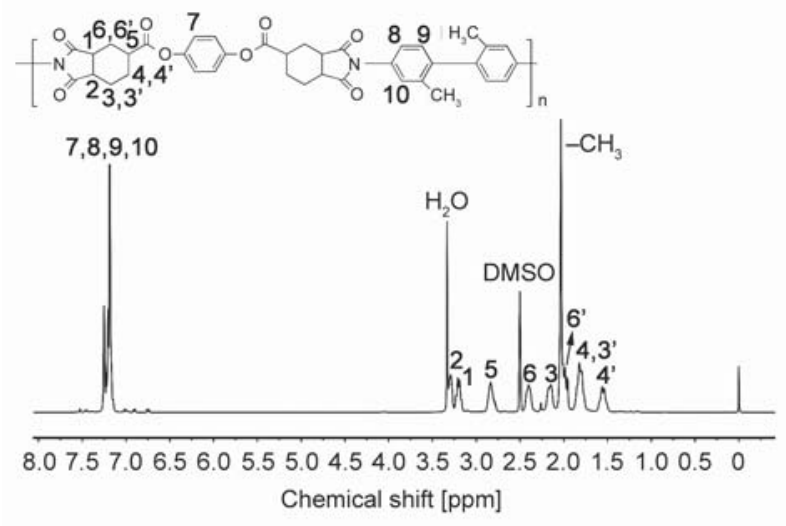

Figure 5. ${ }^{1} \mathrm{H}-\mathrm{NMR}$ spectra of $\mathrm{PI}-\mathrm{I}_{\mathrm{b}}$. via the polymerization. Furthermore, the absorptions ascribed to the $\mathrm{C}=\mathrm{C}$ bonds in the phenyl or biphenyl units $\left(1495 \mathrm{~cm}^{-1}\right)$, the $\mathrm{C}-\mathrm{O}-\mathrm{C}$ bonds in the ester moiety $\left(1146 \mathrm{~cm}^{-1}\right)$, and the saturated $\mathrm{C}-\mathrm{H}$ bonds in the cyclohexane unit $\left(2949 \mathrm{~cm}^{-1}\right)$ maintained in both of the spectra of the dianhydrides and the derived PIs. The chemical structures of the PIs were further determined by the NMR technique. The typical ${ }^{1} \mathrm{H}-\mathrm{NMR}$ spectra of PI- $\mathrm{I}_{\mathrm{b}}$ is shown in Figure 5. Similarly to the ${ }^{1} \mathrm{H}-\mathrm{NMR}$ spectra of the dianhydride monomers, the spectra of the polymers also consisted of two regions, including the low-field aromatic protons (7.0$8.0 \mathrm{ppm})$ and the high-field alicyclic ones (1.5$3.5 \mathrm{ppm})$. The protons close to the electron-withdrawing $-\mathrm{CF}_{3}\left(\mathrm{H}_{10}\right.$ for $\left.\mathrm{PI}-\mathrm{I}_{\mathrm{b}}\right)$ exhibited absorptions at the lowest field in the spectra; while the protons in the cyclohexane ring appeared at the highest field positions. In addition, the stereoscopic conformation of the cyclohexane unit still existed in the PIs with the individual absorptions for $\mathrm{H}_{3,3^{\prime}}, \mathrm{H}_{4,4^{\prime}}$, and $\mathrm{H}_{6,6^{\prime}}$. All the measurements revealed the successful preparation of the semi-alicyclic PI resin.

\subsection{Polyimide fabrics preparation and characterization}

It has been well established that the appropriate spinning solution properties, including the solid contents, absolute viscosities, and characters of the solvents are critical factors affecting the quality of the derived electrospinning fabrics. In order to achieve high quality of the ultrafine non-woven fabrics, the solubility, and viscosity-solid contents relationship of the PI resins were investigated.

First, the solubility of the PI resins in typical solvents was measured and the result was tabulated in Table 2. The fully-dried PI resins were soluble in polar aprotic $N$-methyl-2-pyrollidinone (NMP), $N, N$-dimethylforamide (DMF), and $N, N$-dimethylacetamide (DMAc) at a solid content of $10 \mathrm{wt} \%$ except PI- $\mathrm{I}_{\mathrm{a}}$, which was only soluble in NMP. PIs derived from TFMB were also soluble in less polar $\gamma$-butyrolactone (GBL) and $m$-cresol. PI- II $_{\mathrm{b}}$ derived from HTA$\mathrm{BP}$ and TFMB showed the best solubility in the series, which was also soluble in chloroform at room temperature. All the PI resins are not soluble in butyl cellosolve (BC), which is usually used as a leveling agent for PI solution.

Secondly, solvents with suitable boiling point and vapor pressure need to be elaborately selected for the electrospinning procedure of polymer solutions. 
Table 2. Solubility of the PI resins.

\begin{tabular}{|c|c|c|c|c|c|c|c|c|}
\hline \multirow{2}{*}{ PI } & \multicolumn{8}{|c|}{ Solvent $^{\mathrm{a}}$} \\
\hline & NMP & DMAc & DMF & GBL & BC & $m$-cresol & THF & $\mathrm{CHCl}_{3}$ \\
\hline $\mathrm{PI}-\mathrm{I}_{\mathrm{a}}$ & $++^{b}$ & + & + & + & - & + & - & - \\
\hline $\mathrm{PI}-\mathrm{I}_{\mathrm{b}}$ & ++ & ++ & ++ & ++ & - & ++ & + & + \\
\hline PI-II & ++ & ++ & ++ & + & - & + & - & + \\
\hline PI-II & ++ & ++ & ++ & ++ & - & ++ & ++ & ++ \\
\hline
\end{tabular}

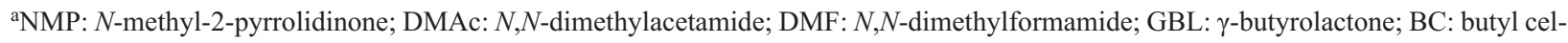
losolve; THF: tetrahydrofuran;

$\mathrm{b}_{++}$: Wholly soluble at room temperature; +-: Partially soluble; -: Insoluble.

Solvents with exorbitant boiling point or extreme low vapor pressure might cause the residual solvents in the final fabrics; thus deteriorating their physical and chemical properties. In the current research, DMAc was chosen as the solvent for the preparation of PI spinning agents due to its suitable boiling point (boiling point: $165-166^{\circ} \mathrm{C}$ at $101.3 \mathrm{kPa}$ ) and vapor pressure $\left(0.17 \mathrm{kPa}\right.$ at $\left.25^{\circ} \mathrm{C}\right)$. Due to this reason, three PI resins (without PI- $\mathrm{I}_{\mathrm{a}}$ for its limited solubility in DMAc) were dissolved in DMAc and afforded the spinning agents for the following electrospinning fabrication.

Finally, the viscosity-solid content relationship of the PI spinning agents was investigated. Suitable viscosity is critical for obtaining non-woven fabrics with uniform microstructure. As we know, non-woven fabrics are web structures bonded together by mechanically entangling fiber or filaments. When the viscosity of the spinning agents was too high, the diameter of the derived electrospun fibers might be thicker; thus decreasing the specific surface areas of the obtained non-woven fabrics. On the contrary, the low viscosity usually afforded electrospun fibers with local defects. In our previous study, the viscosity values of the spinning agents in the range of 8000 $12000 \mathrm{mPa} \cdot \mathrm{s}$ were proven to be optimal for soluble PI electrospinning fabrication [37]. The viscositysolid content relationship of the PI solutions is illustrated in Figure 6. It can be clearly observed that the PI resins exhibited quite different dissolution behaviors in DMAc, although they were all soluble in

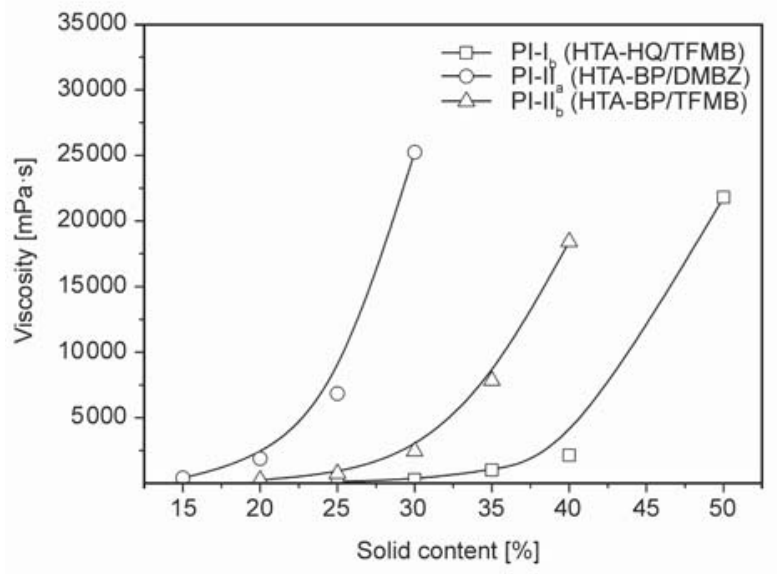

Figure 6. Relationship between viscosity and solid content of PI varnishes.

DMAc. For example, in order to achieve an absolute viscosity of $10000 \mathrm{mPa} \cdot \mathrm{s}$, the solid contents of the PI resins were $26 \mathrm{wt} \%\left(\mathrm{PI}-\mathrm{II}_{\mathrm{a}}\right), 36 \mathrm{wt} \%\left(\mathrm{PI}-\mathrm{II}_{\mathrm{b}}\right)$, and $44 \mathrm{wt} \%\left(\mathrm{PI}-\mathrm{I}_{\mathrm{b}}\right)$, respectively. This is mainly attributed to the molecular weights of the PI resins. PI-II with the highest $M_{\mathrm{n}}$ value exhibited inferior solubility among the resins. Three PI solutions with the individual solid contents and the similar absolute viscosity $(\sim 10000 \mathrm{mPa} \cdot \mathrm{s})$, including PI- $\mathrm{I}_{\mathrm{b}}, \mathrm{PI}-\mathrm{II}_{\mathrm{a}}$, and PI-II $\mathrm{I}_{\mathrm{b}}$ were then made as the spinning agents.

Then, the prepared PI spinning solutions were used as the starting materials for the following electrospinning procedure with the conditions shown in Table 3. Two electrospinning fabrication processes were used in the current work, as depicted in Figure 7. One is the electrospinning procedure via the

Table 3. Electrospinning conditions for PI ultrafine non-woven fabrics.

\begin{tabular}{|c|c|c|c|c|c|c|}
\hline & $\begin{array}{c}\text { Solid content } \\
{[\mathbf{w t} \%]}\end{array}$ & $\begin{array}{c}\text { Applied voltage } \\
{[\mathbf{k V}]}\end{array}$ & $\begin{array}{c}\text { S-C distance } \\
{[\mathbf{c m}]}\end{array}$ & $\begin{array}{c}\text { Feeding rate }_{[\mathbf{m l} / \mathbf{h}]} \\
\text { Inner diameter }^{\mathbf{b}} \\
{[\mathbf{m m}]}\end{array}$ & $\begin{array}{c}\text { Humidity } \\
{[\%]}\end{array}$ \\
\hline $\mathrm{PI}-\mathrm{I}_{\mathrm{b}}$ & 40 & 15 & 15 & 0.1 & 0.5 & $50 \pm 2$ \\
\hline $\mathrm{PI}_{\mathrm{II}} \mathrm{a}$ & 25 & 15 & 15 & 0.1 & 0.5 & $50 \pm 2$ \\
\hline $\mathrm{PI}_{\mathrm{a}} \mathrm{I}$ & 15 & 15 & 0.1 & 0.5 & $50 \pm 2$ \\
\hline $\mathrm{PI}_{\mathrm{b}} \mathrm{ref}$ & 35 & 15 & 15 & 0.1 & 0.5 & $50 \pm 2$ \\
\hline
\end{tabular}

${ }^{\mathrm{a}}$ The distance between the spinneret and the grounded collector.

${ }^{\mathrm{b}}$ The inner diameter of the spinneret. ${ }^{\mathrm{c}} \mathrm{PI}-\mathrm{ref}$ : poly(pyromellitic dianhydride-oxydianiline) (PMDA-ODA). 

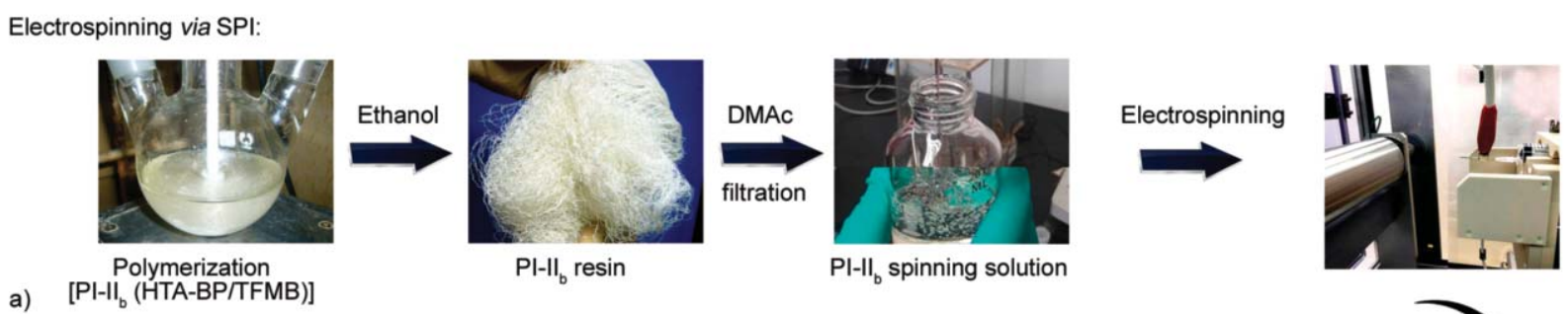

Polymerization
PI-II
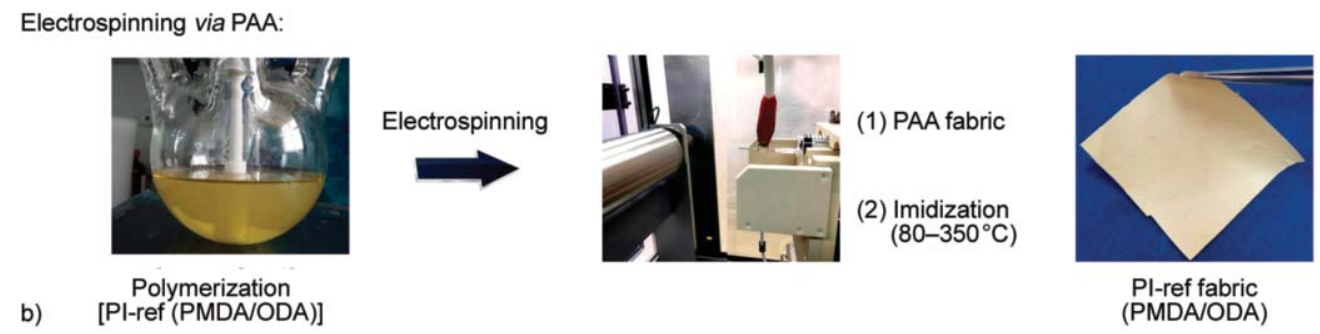

PI-ref fabric (PMDA/ODA)

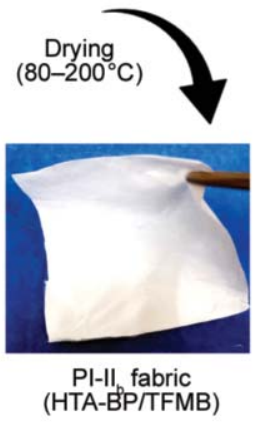

Figure 7. Preparation process for PI non-woven fabrics via SPI or PAA. a) Electrospinning via SPI; b) Electrospinning via PAA.

newly developed preimidized soluble PIs (SPI) (Figure 7a), which is characterized by the relatively lower post-treatment temperature $\left(80-200^{\circ} \mathrm{C}\right)$. In the whole procedure, no chemical reaction occurred. The final thermal treatment is to remove the residual solvent in the fabrics. The obtained PI ultrafine non-woven fabrics, as exemplified by PI-II ${ }_{b}$ (HTA-BP/TFMB), usually exhibited low colors, high whiteness, and good uniformity. The other one is to make the PI fabrics via soluble poly(amic acid) (PAA) precursors (Figure $7 \mathrm{~b}$ ), whose feature is the high temperature imidization reaction in the range of $80-350{ }^{\circ} \mathrm{C}$. During the post-treatment, PAA was thermally dehydrated to afford the final PI fabrics. Thus, the obtained PI fabrics, as illustrated by PI-ref(PMDA-ODA), usually showed colored appearance, somewhat adhesion between the single fiber, and inner pinholes due to the continuous emission of water by-product.

The typical microscopic morphologies of $\mathrm{PI}-\mathrm{II}_{\mathrm{b}}$ (HTA-BP/TFMB) non-woven fabrics with different magnifications are shown in Figure 8. Continuous and smooth fine fibers with the average diameters around $1.1-1.2 \mu \mathrm{m}$ were clearly observed, indicating high molecular weights of the PI resin and suitable electrospinning procedure parameters. Generally speaking, fiber diameter has a significant effect on the optical properties of the electrospun PI fibrous membranes, especially the optical reflectivity. When the fiber diameter is small, it can produce better light scattering effect; thus improving the whiteness of fabrics [46]. The fibers possessed average diameters at a level of micrometers, making them exhibit high specific surface area and good optical reflection.
These characters are usually highly desired for optical applications. At last, no adhesion between the single fibers was observed for the non-woven fabrics, which often occurred for the electrospinning fibers via PAA solutions [41]. It can be expected that the current PI fabrics might have good mechanical properties due to the relatively flawless microscopic morphology of the fibers.

\subsection{Optical properties}

The optical properties of the semi-alicyclic PI ultrafine fabrics were investigated. First, the optical reflection feature of the PI fabrics was evaluated by UV-Vis spectrometer and the spectra and data are presented in Figure 9 and Table 4, respectively. The optical reflectance values of the fabrics at the wavelength of $457 \mathrm{~nm}\left(R_{457}\right)$ are all higher than $89.0 \%$ for the current semi-alicyclic PI fabrics. These data are much higher than that of the wholly aromatic PI-ref $\left(R_{457}=37.3 \%\right)$. The superior optical reflection features of the current PI fibers can be mainly attributed to the absence of visible-light absorption due to the reduced formation of charge transfer complexes (CTC) in the semi-alicyclic PI molecular chains by introduction of nonconjugated cyclohexane units in the dianhydride moiety. In addition, the highly electronegative $-\mathrm{CF}_{3}$ substituents in $\mathrm{PI}-\mathrm{I}_{\mathrm{b}}$ and $\mathrm{PI}-\mathrm{II}_{\mathrm{b}}$ could further reduce the formation of CTCs; thus, both of these two PI fabrics exhibited the highest $R_{457}$ values in the series (Table 4). The high optical reflection characters of the current newly developed PI non-woven fabrics (inserted in Figure 9) are quite beneficial for their potential applications as reflectors for LED fabrication. 


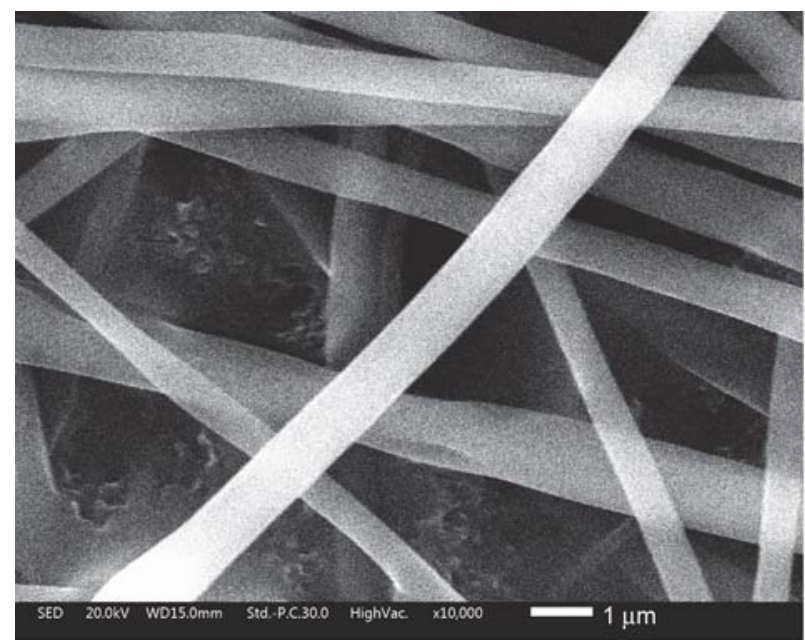

a)

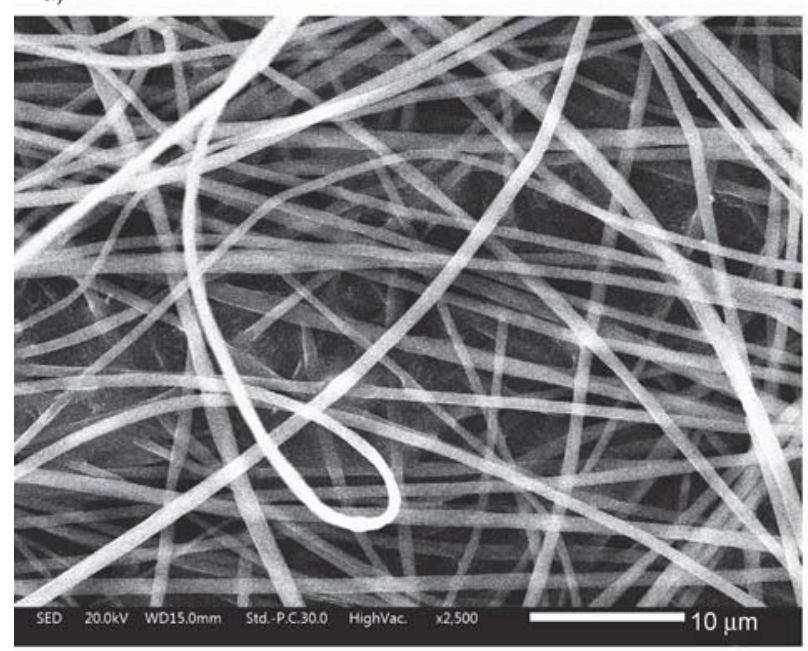

c)

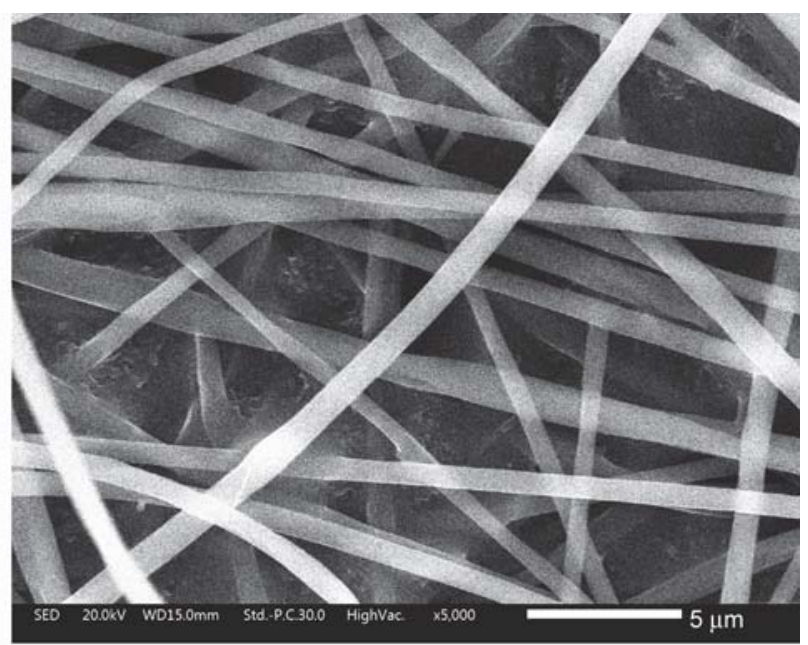

b)

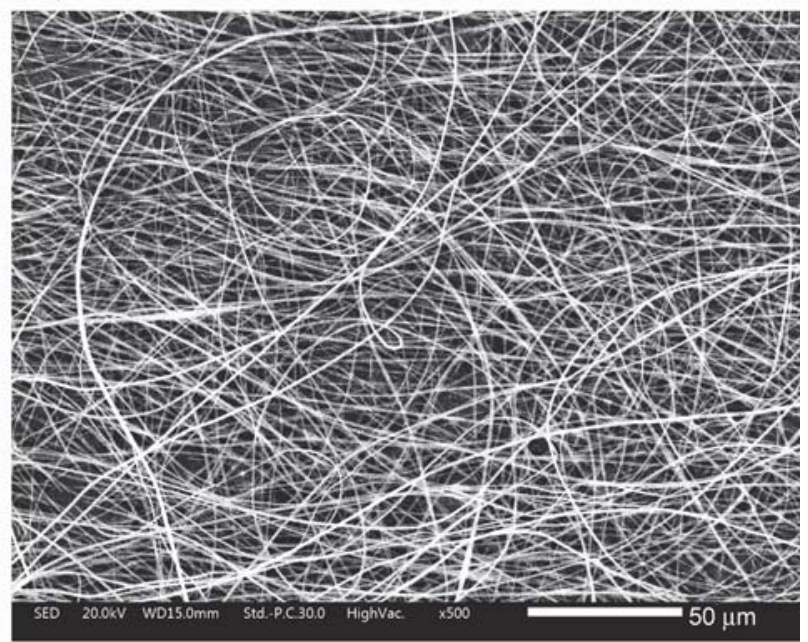

d)

Figure 8. SEM micrographs of PI-II ${ }_{b}$ non-woven fabric. a) $1 \mu \mathrm{m}$; b) $5 \mu \mathrm{m}$; c) $10 \mu \mathrm{m}$; and d) $50 \mu \mathrm{m}$.

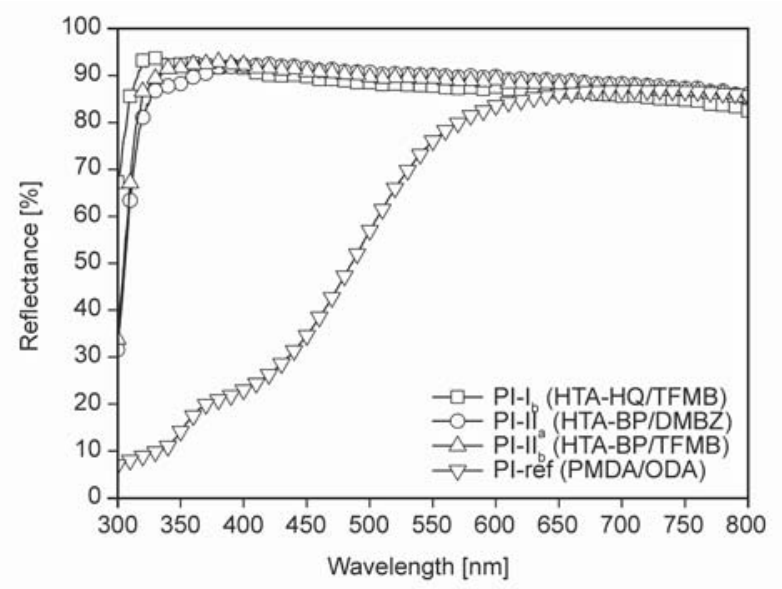

Figure 9. UV-Vis reflectance plots of PI non-woven fabrics.

In order to further clarify the better optical properties of the current semi-alicyclic PI fabrics, the optical parameters, including the whiteness indices $(W I)$ and the yellow indices were quantitatively analyzed by standard CIE lab measurements and the results are tabulated in Table 4 and Figure 10. The semi-alicyclic
Table 4. Optical properties of PI non-woven fabrics.

\begin{tabular}{|l|c|c|c|c|c|c|c|}
\hline & $\begin{array}{c}\boldsymbol{d}^{\mathrm{a}} \\
{[\boldsymbol{\mu \mathrm { m } ]}]}\end{array}$ & $\begin{array}{c}\text { Thickness }^{\mathbf{b}} \\
{[\boldsymbol{\mu \mathbf { m } ]}]}\end{array}$ & $\begin{array}{c}\boldsymbol{R}_{\mathbf{4 5 7}}^{\mathrm{c}} \\
{[\mathbf{\%}]}\end{array}$ & $\boldsymbol{L}^{*}$ & $\boldsymbol{a}^{*}$ & $\boldsymbol{b}^{*}$ & $\boldsymbol{W I}^{\mathbf{d}}$ \\
\hline $\mathrm{PI}^{\mathrm{I}} \mathrm{\textrm {b }}$ & 1.1 & 22 & 89.3 & 91.80 & -0.30 & 1.11 & 91.7 \\
\hline $\mathrm{PI}_{\mathrm{II}} \mathrm{a}$ & 1.2 & 21 & 91.4 & 92.79 & -0.37 & 1.36 & 92.5 \\
\hline $\mathrm{PI}_{\mathrm{II}}$ & 1,2 & 22 & 90.6 & 92.66 & -0.40 & 1.40 & 92.7 \\
\hline PI-ref $^{\mathrm{e}}$ & 1.2 & 23 & 37.3 & 84.65 & 1.62 & 37.96 & 59.0 \\
\hline
\end{tabular}

${ }^{a} d$ : average diameter of PI fiber;

${ }^{\mathrm{b}}$ Thickness of PI fabrics;

${ }^{\mathrm{c}} R_{457}$ : Reflectance at $457 \mathrm{~nm}$ measured with mats;

${ }^{\mathrm{d}}$ WI: whiteness index;

ePI-ref: poly(pyromellitic dianhydride-oxydianiline) (PMDAODA).

PI fabrics showed WI values higher than 91.0, whereas PI-ref showed a much lower value of 59.0. Generally, the whiteness of polymer ultrafine fabrics is dominated by both of physical and chemical effects [17]. One can sometimes achieve high whiteness of specific polymer ultrafine fabrics by adjustment of the diameters and microscopic morphology of the 

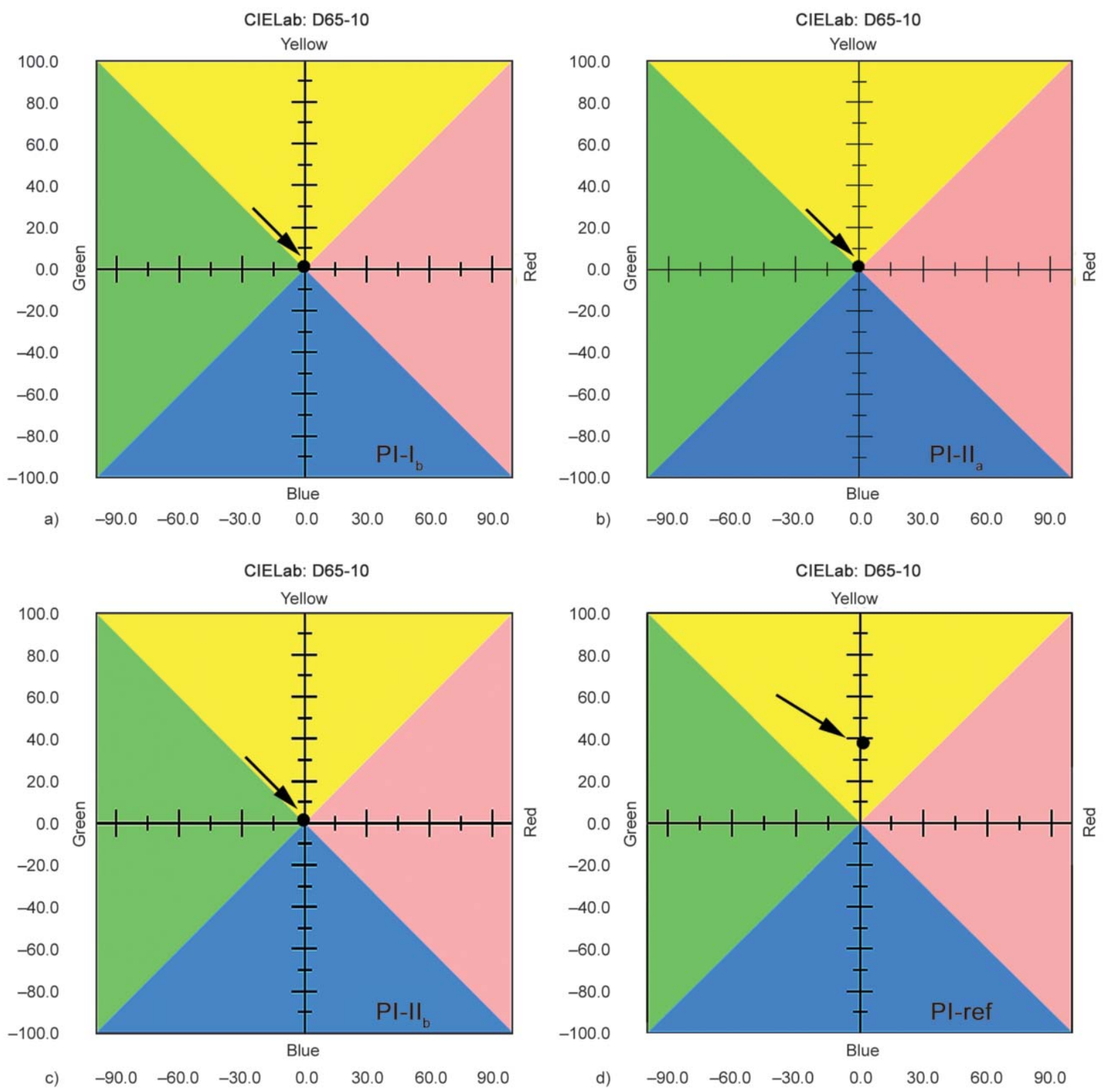

Figure 10. Color parameters of the PI non-woven fabrics via CIE Lab measurements. a) PI-Ib; b) PI-IIa; c) PI-IIb; and d) PI-ref.

fibers, which is by physical modification. However, this method usually suffers from the very limited adjustment levels, especially for polymers with intrinsically colored features, such as the standard wholly aromatic PIs. In the current work, high whiteness was designed to be achieved for the derived PI non-woven fabrics via both of physical adjustment and chemical modification procedures. On one hand, the diameters and morphography of the fibers were controlled by tailoring the viscosity and solid contents of the PI spinning solutions in order to afford optimal photo scattering features. On the other hand, the molecular structure of the PIs was elaborately designed so as to eliminate or decrease the absorption of visible light. The purpose has been proven to be effective because that the wholly aromatic PI-ref exhibited obvious inferior whiteness $(W I=59.0)$ to the semi-alicyclic analogues $(W I>91.0)$ although they possessed similar physical fiber parameters (Table 4).

\subsection{Thermal properties}

Thermal stability is another important factor determining whether the high-whiteness non-woven fabrics could be used as reflectors or not. Although the standard wholly aromatic PIs are known for the excellent thermal stability, the modification aiming at reducing the intra- and intermolecular CTC formation usually sacrifice the intrinsic thermal resistance of the PIs. The TGA and DSC plots of the semi-alicyclic PI non-woven fabrics are shown in Figure 11 


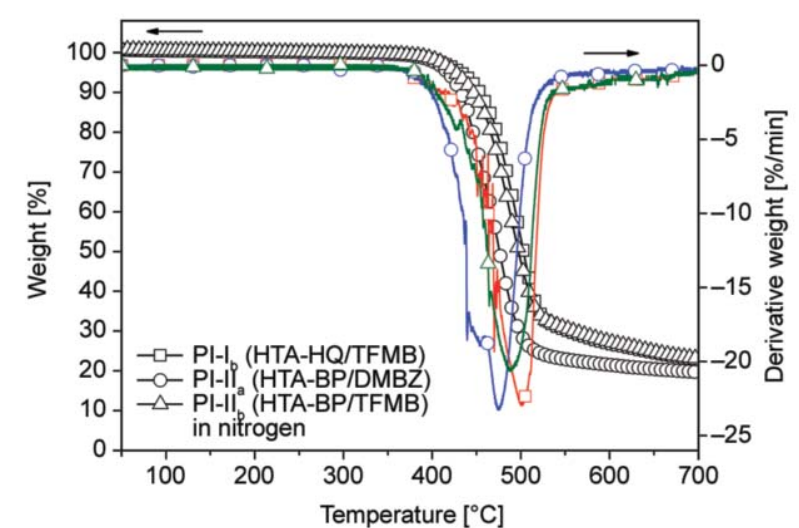

Figure 11. TGA and differential TGA curves of PI nonwoven fabrics in nitrogen environment.

and Figure 12, respectively and the thermal data are summarized in Table 5.

The PI fabrics exhibited good thermal stability up to $400^{\circ} \mathrm{C}$ and rapidly decomposed after $450^{\circ} \mathrm{C}$, leaving about $20 \mathrm{wt} \%$ of their original weights at $700^{\circ} \mathrm{C}$ in nitrogen (Figure 11). It is clear from the differential TGA data that all the PI fabrics showed a singlestage decomposition process during the heating in the nitrogen atmosphere and the maximum decomposition speed occurred around $450-500^{\circ} \mathrm{C}$.

The good thermal stability of the current PI fabrics can mainly be attributed to the synergic effects of rigid biphenylene units in the diamine moiety and ester linkages in the dianhydride moiety. The 5\% weight loss temperatures $\left(T_{5 \%}\right)$ of the PI fabrics decreased with the order of PI- $\mathrm{I}_{\mathrm{b}}\left(432.3^{\circ} \mathrm{C}\right)>\mathrm{PI}^{-\mathrm{II}_{\mathrm{b}}}$ $\left(426.1^{\circ} \mathrm{C}\right)>\mathrm{PI}^{-\mathrm{II}_{\mathrm{a}}}\left(417.8^{\circ} \mathrm{C}\right) . \mathrm{PI}-\mathrm{I}_{\mathrm{b}}$ with both of the rigid biphenylene units and thermal stable $-\mathrm{CF}_{3}$ substituents in the diamine segments exhibited the highest $T_{5 \%}$ value.

The glass transition temperatures $\left(T_{\mathrm{g}}\right)$ of the PI fabrics were recorded by the DSC measurements. The PI fabrics showed $T_{\mathrm{g}}$ values in the range of 217.4$241.9^{\circ} \mathrm{C}$ and increased according to the sequence of

Table 5. Thermal properties of PI non-woven fabrics.

\begin{tabular}{|c|c|c|c|c|}
\hline & $\begin{array}{c}\boldsymbol{T}_{\mathbf{g}} \mathbf{a} \\
{\left[{ }^{\mathbf{a}} \mathbf{C}\right]}\end{array}$ & $\begin{array}{c}\boldsymbol{T}_{\mathbf{5} \%}{ }^{\mathbf{b}} \\
{\left[{ }^{\circ} \mathbf{C}\right]}\end{array}$ & $\begin{array}{c}\boldsymbol{T}_{\mathbf{1 0 \%}}{ }^{\mathbf{b}} \\
{\left[{ }^{\circ} \mathbf{C}\right]}\end{array}$ & $\begin{array}{c}\boldsymbol{R}_{\mathbf{w 7 0 0}}{ }^{\mathbf{c}} \\
{[\mathbf{\%}]}\end{array}$ \\
\hline $\mathrm{PI}^{\mathbf{c}} \mathrm{I}_{\mathrm{b}}$ & 218.9 & 432.3 & 453.6 & 22.9 \\
\hline $\mathrm{PI} \mathrm{II}_{\mathrm{a}}$ & 217.4 & 417.8 & 432.2 & 19.7 \\
\hline $\mathrm{PI}_{\mathrm{II}} \mathrm{II}_{\mathrm{b}}$ & 241.9 & 426.1 & 445.9 & 23.1 \\
\hline
\end{tabular}

${ }^{\mathrm{a}} T_{\mathrm{g}}$ : Glass transition temperatures measured by DSC;

${ }^{\mathrm{b}} T_{5 \%}, T_{10 \%}$ : Temperatures at $5 \%$ and $10 \%$ weight loss, respectively;

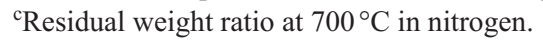

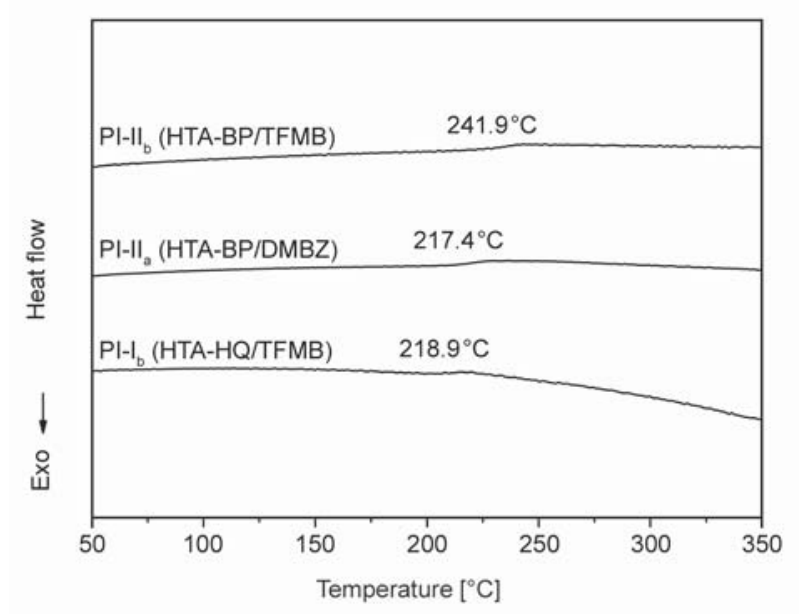

Figure 12. DSC curves for PI non-woven fabrics.

PI-II ${ }_{\mathrm{a}}\left(217.4^{\circ} \mathrm{C}\right)<\mathrm{PI}^{-\mathrm{I}_{\mathrm{b}}}\left(218.9^{\circ} \mathrm{C}\right)<\mathrm{PI}-\mathrm{II}_{\mathrm{b}}\left(241.9^{\circ} \mathrm{C}\right)$. $\mathrm{PI}-\mathrm{II}_{\mathrm{b}}$ with the rigid biphenylene units in both of the dianhydride and diamine segments exhibited the highest $T_{\mathrm{g}}$ value. The thermal data revealed that the current PI fabrics possessed good thermal stability for their potential applications as reflectors for LED devices.

\section{Conclusions}

A series of semi-alicyclic PI ultrafine non-woven fabrics with high whiteness and good thermal stability were successfully prepared via electrospinning fabrication of SPI solution, followed by post thermal treatment at relatively low temperature $\left(\leq 200^{\circ} \mathrm{C}\right)$. Such procedure showed superior advantages to the conventional PAA route in the research and development of high performance non-woven fabrics for optical applications. The obtained PI fabrics exhibited high optical reflectance $\left(R_{457}>89 \%\right)$, high whiteness $(W I>91.0)$, and good thermal stability $\left(T_{5 \%}>\right.$ $417^{\circ} \mathrm{C} ; T_{\mathrm{g}}>217^{\circ} \mathrm{C}$ ). Good comprehensive properties make the current non-woven fabrics good candidates for optical fabrications, such as reflectors for LED devices. The corresponding work is carried out in our lab and the application of the current PI fabrics will be reported in near future.

\section{Acknowledgements}

Financial support from the Fundamental Research Funds of China University of Geosciences, Beijing (No. 2652017345) is gratefully acknowledged. 


\section{References}

[1] Liaw D-J., Wang K-L., Huang Y-C., Lee K-R., Lai J-Y., Ha S-K.: Advanced polyimide materials: Syntheses, physical properties and applications. Progress in Polymer Science, 37, 907-974 (2012).

https://doi.org/10.1016/j.progpolymsci.2012.02.005

[2] Tsai C-L., Yen H-J., Liou G-S.: Highly transparent polyimide hybrids for optoelectronic applications. Reactive and Functional Polymers, 108, 2-30 (2016). https://doi.org/10.1016/j.reactfunctpolym.2016.04.021

[3] Ni H-J., Liu J-G., Wang Z-H., Yang S-Y.: A review on colorless and optically transparent polyimide films: Chemistry, process and engineering applications. Journal of Industrial and Engineering Chemistry, 28, 16-27 (2015). https://doi.org/10.1016/j.jiec.2015.03.013

[4] Volksen W., Miller R-D., Dubois G.: Low dielectric constant materials. Chemical Reviews, 110, 56-110 (2010). https://doi.org/10.1021/cr9002819

[5] Zhao G., Ishizaka T., Kasai H., Hasegawa M., Furukawa T., Nakanishi H., Oikawa H.: Ultralow-dielectric-constant films prepared from hollow polyimide nanoparticles possessing controllable core sizes. Chemistry of Materials, 21, 419-424 (2009). https://doi.org/10.1021/cm802989u

[6] Hasegawa M., Horie K.: Photophysics, photochemistry, and optical properties of polyimides. Progress in Polymer Science, 26, 259-335 (2001). https://doi.org/10.1016/S0079-6700(00)00042-3

[7] Chang S-W., Huang T-T., Tsai C-L., Liou G-S.: Highly transparent polyhydroxyimide $/ \mathrm{TiO}_{2}$ and $\mathrm{ZrO}_{2}$ hybrid films with high glass transition temperature $\left(T_{\mathrm{g}}\right)$ and low coefficient of thermal expansion (CTE) for optoelectronic application. Journal of Material Chemistry, C, 5, 8444-8453 (2017). https://doi.org/10.1039/c7tc02819a

[8] Kumar S-V., Yu H-C., Choi J., Kudo K., Jang Y-H., Chung C-M.: Structure-property relationships for partially aliphatic polyimides. Journal of Polymer Research, 18, 1111-1117 (2011). https://doi.org/10.1007/s10965-010-9513-2

[9] Ke F., Song N., Liang D., Xu H.: A method to break charge transfer complex of polyimide: A study on solution behavior. Journal of Applied Polymer Science, 127, 797-803 (2013). https://doi.org/10.1002/app.37782

[10] Yang Y., Jung Y., Cho M-D., Lee S-G., Kwon S.: Transient color changes in oxidative-stable fluorinated polyimide film for flexible display substrates. RSC Advances, 5, 57339-57345 (2015). https://doi.org/10.1039/c5ra06066d

[11] Choi M-C., Hwang J-C., Kim C., Ando S., Ha C-S.: New colorless substrates based on polynorbornenechlorinated polyimide copolymers and their application for flexible displays. Journal of Polymer Science Part A: Polymer Chemistry, 48, 1806-1814 (2010). https://doi.org/10.1002/pola.23949
[12] Hasegawa M., Watanabe Y., Tsukuda S., Ishii J.: Solution-processable colorless polyimides with ultralow coefficients of thermal expansion for optoelectronic applications. Polymer International, 65, 1063-1073 (2016). https://doi.org/10.1002/pi.5152

[13] Hasegawa M.: Development of solution-processable, optically transparent polyimides with ultra-low linear coefficients of thermal expansion. Polymers, 9, 520/1520/31 (2017).

https://doi.org/10.3390/polym9100520

[14] Yu Y., Shen W., Li F., Fang X., Duan H., Xu F., Xiong Y., Xu W., Song W-J.: Solution-processed multifunctional transparent conductive films based on long silver nanowires/polyimide structure with highly thermostable and antibacterial properties. RSC Advances, 7, 28670 28676 (2017).

https://doi.org/10.1039/c7ra04569g

[15] Matsumoto T., Mikami D., Hashimoto T., Kaise M., Takahashi R., Kawabata S.: Alicyclic polyimides - A colorless and thermally stable polymer for opto-electronic devices. Journal of Physics: Conference Series, 187, 012005/1-012005/11 (2009). https://doi.org/10.1088/1742-6596/187/1/012005

[16] Tang Y., Liang G., Chen J., Yu S., Li Z., Rao L., Yu B.: Highly reflective nanofiber films based on electrospinning and their application on color uniformity and luminous efficacy improvement of white light-emitting diodes. Optical Express, 25, 20598-20611 (2017). https://doi.org/10.1364/OE.25.020598

[17] Yip J., Ng S-P., Wong K-H.: Brilliant whiteness surfaces from electrospun nanofiber webs. Texture Research Journal, 79, 771-779 (2009). https://doi.org/10.1177/0040517509102797

[18] Abbas A., Zhao Y., Ali U., Lin T.: Improving heat-retaining property of cotton fabrics through surface coatings. Journal Textile Institute, 108, 1808-1814 (2017). https://doi.org/10.1080/00405000.2017.1292638

[19] Hua T., Tang L-Y., Chiu W-Y., Tian X.: Color attributes of colored-yarn mixed woven fabrics made of rawwhite warps and multicolored wefts and based on weftbacked structures. Polymers, 10, 146/1-146/17 (2018). https://doi.org/10.3390/polym10020146

[20] Stavenga D-G., Stowe S., Siebke K., Zeil J., Arikawa K.: Butterfly wing colours: Scale beads make white pierid wings brighter. Proceedings of the Royal Society B: Biological Sciences, 271, 1577-1584 (2004). https://doi.org/10.1098/rspb.2004.2781

[21] Agubra V-A., Zuniga L., Flores D., Villareal J., Alcoutlabi M.: Composite nanofibers as advanced materials for Li-ion, $\mathrm{Li}-\mathrm{O}_{2}$ and Li-S batteries. Electrochimica Acta, 192, 529-550 (2016). https://doi.org/10.1016/j.electacta.2016.02.012

[22] Chen F., Bera D., Banerjee S., Agarwal S.: Low dielectric constant polyimide nanomats by electrospinning. Polymers for Advanced Technologies, 23, 951-957 (2012). https://doi.org/10.1002/pat.1997 
[23] Shirazi M-M. A., Kargari A., Ramakrishna S., Doyle J., Rajendrian M., Babu P. R.: Electrospun membranes for desalination and water/wastewater treatment: A comprehensive review. Journal of Membrane Science and Research, 3, 209-227 (2017).

https://doi.org/10.22079/jmsr.2016.22349

[24] Oktay B., Toker R-D., Kayaman-Apohan N.: Superhydrophobic behavior of polyimide-siloxane mats produced by electrospinning. Polymer Bulletin, 72, $2831-$ 2842 (2015).

https://doi.org/10.1007/s00289-015-1438-9

[25] Liao X., Ye W., Chen L., Jiang S., Wang G., Zhang L., Hou H.: Flexible hdC-G reinforced polyimide composites with high dielectric permittivity. Composites Part A: Applied Science and Manufacturing, 101, 50-58 (2017). https://doi.org/10.1016/j.compositesa.2017.06.011

[26] Duan G., Liu S., Jiang S., Hou H.: High-performance polyamide-imide films and electrospun aligned nanofibers from an amide-containing diamine. Journal of Materials Science, 54, 6719-6727 (2019). https://doi.org/10.1007/s10853-019-03326-w

[27] Jiang S., Chen Y., Duan G., Mei C., Greiner A., Agarwal S.: Electrospun nanofiber reinforced composites: A review. Polymer Chemistry, 9, 2685-2720 (2018). https://doi.org/10.1039/C8PY00378E

[28] Chen Y., Sui L., Fang H., Ding C-H., Li Z-K., Jiang S-H., Hou H-Q.: Superior mechanical enhancement of epoxy composites reinforced by polyimide nanofibers via a vacuum-assisted hot-pressing. Composites Science and Technology, 174, 20-26 (2019). https://doi.org/10.1016/j.compscitech.2019.02.012

[29] Jiang S-H., Uch B., Agarwal S., Greiner A.: Ultralight, thermally insulating, compressible polyimide fiber assembled sponges. ACS Applied Materials and Interfaces, 9, 32308-32315 (2017). https://doi.org/10.1021/acsami.7b11045

[30] Ye W., Zhu J., Liao X., Jiang S., Li Y., Fang H., Hou H.: Hierarchical three-dimensional micro/nano-architecture of polyaniline nanowires wrapped-on polyimide nanofibers for high performance lithium-ion battery separators. Journal of Power Sources, 299, 417-424 (2015). https://doi.org/10.1016/j.jpowsour.2015.09.037

[31] Jiang S., Hou H., Agarwal S., Greiner A.: Polyimide nanofibers by 'Green' electrospinning via aqueous solution for filtration applications. ACS Sustainable Chemistry and Engineering, 4, 4797-4804 (2016). https://doi.org/10.1021/acssuschemeng.6b01031

[32] Ding Y., Hou H., Zhao Y., Zhu Z., Fong H.: Electrospun polyimide nanofibers and their applications. Progress in Polymer Science, 61, 67-103 (2016). https://doi.org/10.1016/j.progpolymsci.2016.06.006

[33] Kenry, Lim C-T.: Nanofiber technology: Current status and emerging developments. Progress in Polymer Science, 70, 1-17 (2017).

https://doi.org/10.1016/j.progpolymsci.2017.03.002
[34] Spechler J-A., Koh T-W., Herb J-T., Rand B-P., Arnold C. B.: A transparent, smooth, thermally robust, conductive polyimide for flexible electronics. Advanced Functional Materials, 25, 7428-7434 (2015). https://doi.org/10.1002/adfm.201503342

[35] Wu X., Liu J., Jiang G., Zhang Y., Guo C., Zhang Y., Qi L., Zhang X.: Highly transparent preimidized semialicyclic polyimide varnishes with low curing temperatures and desirable processing viscosities at high solid contents: Preparation and applications for LED chip passivation. Journal of Materials Science: Materials in Electronics, 30, 549-560 (2019).

https://doi.org/10.1007/s10854-018-0321-5

[36] Zhang Y., Liu J., Wu X., Bi H., Jiang G., Zhi X-X., Qi L., Zhang X.: Synthesis and characterization of thianthrene-containing preimidized soluble polyimide resins and the derived films with high refractive indices and good optical transparency. Journal of Polymer Research, 26, 2/1-2/11 (2019). https://doi.org/10.1007/s10965-018-1664-6

[37] Guo C-Y., Liu J-G., Yin L-M., Huangfu M-G., Zhang Y., Wu X., Zhang X-M.: Preparation and characterization of electrospun polyimide microfibrous mats with high whiteness and high thermal stability from organosoluble polyimides containing rigid-rod moieties. Fibers and Polymers, 19, 1706-1714 (2018). https://doi.org/10.1007/s12221-018-8270-4

[38] Huang C., Wang S., Zhang H., Li T., Chen S., Lai C., Hou H.: High strength electrospun polymer nanofibers made from BPDA-PDA polyimide. European Polymer Journal, 42, 1099-1104 (2006).

https://doi.org/10.1016/j.eurpolymj.2005.11.005

[39] Yao J., Bastiaansen C-W. M., Peijs T.: High strength and high modulus electrospun nanofibers. Fibers, 2, 158-186 (2014). https://doi.org/10.3390/fib2020158

[40] Yao J., Pantano M. F., Pugno N. M., Bastiaansen C-W. M., Peijs T.: High-performance electrospun co-polyimide nanofibers. Polymer, 76, 105-112 (2015). https://doi.org/10.1016/j.polymer.2015.08.053

[41] Goponenko A-V., Hou H., Dzenis Y-A.: Avoiding fusion of electrospun 3,3',4,4'-biphenyltetracarboxylic dianhydride-4,4'-oxydianiline copolymer nanofibers during conversion to polyimide. Polymer, 52, 3776-3782 (2011). https://doi.org/10.1016/j.polymer.2011.06.023

[42] Guo C-Y., Wu X., Liu J-G., Zhang Y., Zhang X-M.: Preparation and properties of high-whiteness polyimide ultrafine fabrics by electrospinning from organo-soluble semi-alicyclic polyimide resins. Journal of Photopolymer Science and Technology, 31, 27-36 (2018). https://doi.org/10.2494/photopolymer.31.27

[43] Hasegawa M., Kasamatsu K., Koseki K.: Colorless poly (ester imide)s derived from hydrogenated trimellitic anhydride. European Polymer Journal, 48, 483-498 (2012). https://doi.org/10.1016/j.eurpolymj.2011.11.008 
[44] Wang Q., Jian Z., Song W-L., Zhang S., Fan L-Z.: Facile fabrication of safe and robust polyimide fibrous membrane based on triethylene glycol diacetate-2propenoic acid butyl ester gel electrolytes for lithiumion batteries. Electrochimica Acta, 149, 176-185 (2014). https://doi.org/10.1016/j.electacta.2014.10.087

[45] Zhou Y., Chen G., Wang W., Wei L, Zhang Q., Song L., Fang X.: Synthesis and characterization of transparent polyimides derived from ester-containing dianhydrides with different electron affinities. RSC Advances, 5, 79207-79215 (2015).

https://doi.org/10.1039/C5RA16574A
[46] Toivonen M-S., Onelli O-D., Jacucci G., Lovikka V., Rojas O-J., Ikkala O., Vignolini S.: Anomalous-diffusion-assisted brightness in white cellulose nanofibril membranes. Advanced Materials, 30, 1704050/11704050/7 (2018).

https://doi.org/10.1002/adma.201704050 